\title{
Arthritis and Its Solutions
}

\section{Parvez Salim*}

Department of physiotherapist, Bhaichung Bhutia Football Schools, India

*Corresponding Author: Parvez Salim, Department of physiotherapist, Bhaichung Bhutia Football Schools, India.

Received: July 25, 2019; Published: August 13, 2019

\section{Osteoarthritis}

Osteoarthritis prevalence of $22 \%$ to $39 \%$ in India. OA is more common in women than men. Nearly, $45 \%$ of women over the age of 65 years have symptoms while $70 \%$ of those over 65 years show radiological evidence of $\mathrm{OA}$.

Our joint cartilage is disrupted in osteoarthritis and it is the most common form of arthritis. Damage to surface lining of articular cartilage after the compressive forces have surpassed the unit load. Leads to pain, swelling and stiffness, typically affecting the hands, knees, hips, and spine. Radiographic findings on x-ray study include joint space narrowing, osteophyte formation, and subchondral sclerosis and cyst.

- $\quad$ Only you get any disease and illness when you come into high stress and only 3 types of stress are there- physical, chemical and emotional.

- $\quad$ Physical stress when you doing too much of any physical activity and not get enough rest, awkward body position while walking sitting and running.

- Chemical stress is when you eat fast food more and use unhealthy cooking oil and excess of sugar.

- $\quad$ Taking drug of no use do more harm.

- Emotional stress is when you think of so much about their jobs relationship and office work load.

\section{Chemical stress solution}

- Joint cartilage is gets nutrition from synovial fluid.

- Synovial fluid is a ultrafiltration of blood. If we have healthy blood then we have healthy synovial fluid. Healthy synovial fluid lead to healthy joint.

- You can get healthy blood by eating healthy foods.

\section{The list here}

- $\quad$ Dark leafy green vegetables- kale, spinach, beet green, collard green, swiss chard, cabbage, mustard green
- Healthy oil like- olive oil, coconut oil, sesame oil and walnut oil (omega 3 oil)

- $\quad$ Fresh seasonal fruits

- Turmeric a powerful antioxidant, and anti inflammatory properties.

- $\quad$ Turmeric and little bit Himalayan pink salt fluoride free with hot water

- $\quad$ No simple carbohydrate or sugar in your diet at all.

\section{Physical stress solution}

- Synovial fluid is cleared through lymphatics in the synovium, assisted by joint movement. Joint movement is essential to get moving of synovial fluid inside the joint.

- $\quad$ The movement like - walking, jogging doing some exercise according to your level of pain.

- A good posture while doing your physical activities.

- $\quad$ Take a break and walk for 5 min from sitting position after 30 min while doing any work in office or in home.

- $\quad$ Do some stretching and deep breathing on your 5 min break time.

- $\quad$ Simple stretching is Tadasana with deep breathing is good.

- Some calf and hamstring stretching every day at home

- $\quad$ Pelvic bridging

- $\quad$ Front, side and back leg lift from lying position.

- Barefoot walking in ground.

- $\quad$ Some foot exercise like towel toe crunching.

- Get advice from a good physiotherapist about some strength training for your leg also.

Emotional stress solution

- If you are emotionally stress too much then your body release a particular hormone called stress hormone which is not good for your body in too much amount.

- These hormone are always keep you in fight and flight mode and make your arthritic condition worst.

- Meditation is a best way to keep emotional stress away.

- Everyday 10 to 15 min doing meditation keep your brain working more efficiently and productive. 


\section{Holistic approach}

- Should not looking only patient's one condition at a time we should treat whole body. Because may be his or her arthritic condition due to wrong walking pattern and wrong eating habit.

- So by taking care of your chemical, physical and emotional stress not only keep you recover from arthritic pain but also helps in all physical and mental problems.

\section{Drugs and arthritis}

- A study done by American journal of medicine 1999 December.

- Tylenol and NSAIDs causes Arthritis

- Its decrease cartilage production

- Inhibit proteoglycans production (the building blocks of cartilage).

- It causes accelerated bone destruction.

- So according to this study this type of drug can destroy your joint.

\section{Some interesting facts}

- Body wants to heal inflammation by its own.

- Degenerative changes do not appear unless the joint has been damaged by trauma.

- Many elderly joints prove to be just as strong in torsion and compression as the younger ones.

This is typical mechanical characteristic of scar tissue and scar implies injury. (H F FARFAN MANAGING LOW BACK PAIN 2 edition, Churchill Livingston 1988 p.25)

Volume 2 Issue 9 September 2019

(C) All rights are reserved by Parvez Salim. 